\title{
O enigma da aquisição da linguagem de Kaspar Hauser à luz do gerativismo
}

\section{The Kaspar Hauser's language acquisition enigma under the gerativism perspective}

Margarete G. M. de Carvalho ${ }^{1}$, Carmem Elisabete de Oliveira ${ }^{2}$

Mestra em Estudos Linguísticos pela Universidade Federal da Fronteira Sul (2014), especialista em Praticas Pedagogicas Interdisciplinares pelas Faculdades Integradas de Lages (2006) e em Mídias na Educaçăo (2011) pela Universidade Federal do Instituto Federal de Santa Catarin
E-mail: margarete.ifsc@gmail.com

Mestranda em Literatura da Unioeste. Especialista em Interpretação/Traducăão e Docência em Libras pela Universidade TUIUTI (2008) e em Estudos Linguisticos pela Universidade Federal da Frontera Sul (UFFS). Professora de Libras da Un Federal da Fronteira Sul (UFFS).
RESUMO: Este artigo relaciona a trajetória do comportamento linguístico do protagonista do filme de 1974, O Enigma de Kaspar Hauser, do diretor alemão Werner Herzog, aos fenômenos de aquisição da linguagem e da competência linguística inata, postulados pelo gerativismo e investiga como eles se revelam na prática de um falante que adquiriu tardiamente a linguagem verbal. A Teoria Gerativista postula a existência de um dispositivo de aquisição da linguagem com o qual o indivíduo nasce e que, em contato com uma língua natural, gera a gramática da língua a que estiver exposto, desenvolvendo a capacidade de comunicação. 0 presente trabalho é uma análise ficcional em forma de estudo de caso, do tipo descritivo e exploratório, de cunho qualitativo. Esta análise ficcional, relacionada ao gerativismo, corrobora a ideia de que é possível alguém que tenha ficado sem contato com outros humanos, como foi o caso de Kaspar, desenvolver a linguagem verbal ainda que tardiamente, porém com algumas limitações, especialmente relacionadas ao pensamento abstrato que possibilita a compreensão da representatividade dos signos linguísticos.

Palavras-chave: Aquisição da linguagem; Competência linguística; Desempenho linguístico; Gramática Gerativa.

ABSTRACT: This article relates the history of the linguistic behavior of the protagonist of the film The Kaspar Hauser's enigma (1974), of the German director, the phenomena of language acquisition and the innate linguistic competence, postulated by gerativism and investigates how they are revealed in the commission of a speaker who later acquired the verbal language. The Generative Theory postulates the existence of a language acquisition device with $\mathrm{h}$ the individual is born and which, in contact with a natural language, generates the language of grammar that is exposed, developing communication skills. The present work is a fictional analysis in the form of a case study, of the descriptive and exploratory type, of qualitative character. This fictional analysis, related to gerativism, corroborates the idea that it is possible for someone who has been out of touch with other humans, such as Kaspar, to develop verbal language, although late, but that some limitations, especially related to abstract thinking that makes possible the comprehension of the representativeness of the linguistic signs.

Keywords: Language acquisition; Language competence; Linguistic performance; Generative Grammar.

A paisagem em que Kaspar Hauser foi colocado, apesar de explicada pela linguagem, pelas palavras, por signos lingüísticos, permanece, para ele, indecifrável.

(SABOYA, 2001) 


\section{A aquisição tardia da linguagem}

filme O Enigma de Kaspar Hauser tem sido objeto de estudos e análises de diversas áreas das Ciências Sociais. Todas buscam encontrar respostas para o referido enigma, todavia, cada uma com um foco específico. Este artigo se propõe a apresentar pistas que contribuam para desvendar o 'enigma' que está por trás da aquisição e do desenvolvimento da linguagem verbal do protagonista, como demonstrados no filme e em algumas referências bibliográficas que abordam o tema.

A Teoria Gerativa, de Noam Chomsky, enfatiza que o ser humano é dotado geneticamente de uma faculdade específica para o desenvolvimento da linguagem e postula a existência de uma Gramática Universal manifestada por meio das línguas particulares. Assim, este estudo tem como objetivo analisar a trajetória do protagonista do filme, que adquiriu tardiamente a linguagem verbal, identificando aspectos do desenvolvimento da sua habilidade comunicativa, fatores que impuseram restrições ou concorreram para o sucesso desse processo. Buscamos relacionar esses fatores aos pressupostos gerativistas sobre a aquisição da linguagem.

O presente trabalho é uma análise ficcional em forma de estudo de caso, do tipo descritivo e exploratório, de cunho qualitativo. 0 principal instrumento de coleta de dados foi o filme $O$ Enigma de Kaspar Hauser, de Werner Herzog (1974), bem como outras referências sobre a vida do personagem encontradas em fontes como o livro Kaspar Hauser ou a Fabricação da Realidade, de Izidoro Blikstein (1983), o site A autobiografia de Kaspar Hauser (2012) e outras. Para a análise dos dados, foram identificados e listados os aspectos relativos ao recorte do estudo, bem como definidos os conceitos que serviram de base para a interpretação dos fatos (Gramática Universal, Dispositivo Inato para Aquisição da Língua, desempenho linguístico, input, aquisição tardia da linguagem, pobreza de estímulo).
Diante do quadro de aquisição tardia da linguagem apresentado no filme e nas demais fontes de pesquisa sobre o protagonista, algumas questões foram levantadas: a) Seria realmente possível alguém que ficou encarcerado desde a infância até a juventude, sem contato com outros humanos, desenvolver a linguagem verbal em toda a sua complexidade, em tão pouco tempo e com tão limitado estímulo? b) A Teoria Gerativa tem pressupostos que explicam esse fenômeno? c) Como os pressupostos gerativistas da aquisição da linguagem e competência linguística ficam evidentes na prática de um falante que desenvolveu tardiamente a linguagem verbal? São esses os questionamentos para os quais esse artigo se volta, na tentativa de encontrar respostas por meio da Teoria Gerativa.

\section{A aquisição da linguagem e a competência linguística na proposta gerativista}

Noam Chomsky, pesquisador norte-americano, que criou no final dos anos 50 a Teoria Gerativa, conhecida também como Gramática Gerativa, investiga as relações entre mente e língua. Para explicá-las, ele considera a hipótese de que existe, na mente humana, um módulo linguístico responsável pela compreensão e formação de expressões linguísticas, dedicado somente à língua, o qual chama de 'faculdade da linguagem'. Segundo ele, essa faculdade é inata nos seres humanos, e a teoria que designa seu estado inicial denomina-se Gramática Universal. O autor afirma que, em seu estado inicial para aquisição da primeira língua, essa faculdade não difere entre as pessoas, ou seja, conforme esse princípio, qualquer indivíduo apresenta as mesmas condições para desenvolver uma língua, seja ela oral ou sinalizada (CHOMSKY, 2008).

A hipótese inatista de Chomsky ganhou força com a "observação [...] de que os dados dos quais as crianças dispõem com base na fala dos adultos 
parecem inadequados para dar conta do conhecimento que elas adquirem" (TRASK, 2008, p. 35). A esse argumento Chomsky chama de 'pobreza de estímulo'. Trask acrescenta que, segundo o inatismo gerativista, "as crianças já nascem sabendo como são as línguas humanas e apenas precisam adquirir os detalhes da língua que estão aprendendo" (ibid.). Chomsky explica que

A criança vê-se diante dos dados e deve inspecionar hipóteses (gramáticas) de uma classe razoavelmente limitada, para determinar a compatibilidade com esses dados. Tendo escolhido uma gramática da classe predeterminada, terá então domínio da língua gerada por essa gramática. Assim, ela saberá muita coisa sobre fenômenos a que nunca esteve exposta e que não são 'semelhantes' ou 'análogos' em nenhum sentido bem definido àqueles a que esteve exposta. [...] Essa disparidade entre o conhecimento e a experiência talvez seja o fato mais impressionante sobre a linguagem humana (CHOMSKY, 2009, p. 257-258).

Apesar de ter esse dispositivo inato para aquisição da língua (DAL) ${ }^{1}$, o estado inicial dessa faculdade, no indivíduo, sofrerá modificações a ponto de tornar-se a gramática de uma determinada língua, se ele for exposto a um ambiente linguístico apropriado. De acordo com Rosa (2010, p. 56), esse processo "desencadeado pela experiência linguística é fortemente relacionado a processos maturacionais que consistem na sucessão de estágios [...] até o estágio relativamente estável que caracteriza a competência linguística de um falante nativo adulto". Viotti (2008) usa uma analogia para explicar a aquisição da linguagem verbal. Segundo a autora, a língua pode ser comparada a um ser vivo que precisa de nutrientes para se desenvolver; caso contrário, não sobrevive. A autora afirma que:

O mesmo acontece com a informação genética da faculdade da linguagem: em seu estado inicial, que é a gramática universal, ela tem uma prédisposição genética para crescer e se desenvolver e se tornar uma gramática

1 Para saber mais, recomenda-se a leitura de Chomsky (2008). estável, como a do português, do japonês, da LIBRAS, da ASL. Mas, para isso, ela precisa receber nutrientes, ou seja, ela precisa ser exposta a um ambiente lingüístico (sic); se isso não acontecer, essa informação lingüística (sic) inata não vai sobreviver (VIOTTI, 2008, p. 34).

O gerativismo entende que a língua não é aprendida na escola, e sim desenvolvida muito antes, no chamado 'período crítico' para essa aquisição. De acordo com Purves et al. (2005), citado por Rosa (2010, p. 91), esse período de desenvolvimento "pode ser definido como o tempo durante o qual um dado comportamento é especialmente suscetível a influências ambientais específicas - e de fato as requer - para se desenvolver normalmente". Rosa (2010, p. 73) reforça essa ideia, dizendo que, "diferentemente de uma atividade puramente cultural [...], a linguagem é tão profundamente parte da natureza humana que conta com um período sensível para a interação dos aspectos inatos com o ambiente". Diante disso, observa-se que o contexto linguístico em que o indivíduo está inserido é fator determinante no processo de aquisição da língua.

A falta do input linguístico ou a aquisição tardia da língua poderá comprometer o desenvolvimento e desempenho linguístico de um falante. É o que reforça Lyons (2009, p. 183), ao dizer que a mente humana amadurece "de acordo com um programa de desenvolvimento determinado geneticamente interagindo com o ambiente". Isso não quer dizer que uma pessoa privada da interação social não possa vir a desenvolver tardiamente a linguagem, pois sua capacidade inata permanece latente nela. Quadros (2008) chama a atenção para esse fato ao dizer que:

os estudos de aquisição de segunda língua, por exemplo, apresentam várias evidências de que as capacidades latentes são acessadas depois do período crítico, embora os caminhos sejam um pouco diferenciados daqueles possíveis, pelos quais a criança que está adquirindo a linguagem durante o período crítico passaria (QUADROS, 2008, p. 80). 
Chomsky (2009) diferencia os termos 'Competência' e 'Desempenho Linguístico'. A competência, para ele, é o conhecimento linguístico inato que o falante tem e que o capacita a adquirir uma língua, seja ela oral ou sinalizada. Segundo Glenday (2009, p. 9), pode ser entendido como "o conhecimento que o falante possui sobre como produzir e compreender frases". O desempenho é o uso que se faz desse conhecimento, que estará sujeito a fatores psicológicos e sociais que interferirão na externalização da língua.

Em uma situação ilustrativa, pode-se verificar que a competência linguística não está ligada a questões socioculturais, tendo em vista estudos gerativistas comprovarem que uma pessoa com baixo nível de escolarização tem a mesma competência linguística que um universitário (VIOTTI, 2008, p. 35). O que difere, nesse caso, não é a competência, mas o desempenho linguístico do falante. Quanto a este último, Botha (1981, p. 385) destaca ser um fenômeno também complexo, cuja natureza e características são determinadas por uma combinação de fatores. Dentre eles:

a) sua competência linguística ou conhecimento linguístico inconsciente;

b) sua natureza e limitações relacionadas ao discurso de produção e mecanismos de percepção de fala e a aspectos cognitivos, tais como memória, atenção, concentração e outras capacidades mentais;

c) seu ambiente social e status;

d) o ambiente dialetal onde está inserido;

e) ao seu idioleto e estilo individual;

f) o conhecimento factual e a visão do mundo em que vive;

g) seu estado de saúde, estado emocional e outras circunstâncias acidentais semelhantes.

Para Botha (1981), todos esses fatores são variáveis no desempenho linguístico do falante e, como tal, podem influenciar a natureza e as características de um exemplo particular de realização linguística e do(s) seu(s) produto(s).
A Teoria Gerativa postula, portanto, que a capacidade de adquirir uma língua natural não requer a exposição a um ensino sistematizado, pois ela é inata e se desenvolve por meio do input linguístico, ainda que a exposição a ele seja limitada em qualidade e quantidade. 0 mais importante, todavia, é que essa exposição ocorra ainda na infância, período considerado propício para a aquisição da linguagem. Caso ela ocorra em idades mais avançadas, acarretará dificuldades e limitações em sua aquisição.

\section{Aspectos linguísticos do enigma de Kaspar Hauser}

Dentre os diversos relatos sobre a vida de Kaspar Hauser, o filme $O$ Enigma de Kaspar Hauser mostra que ele viveu em um porão, na Baviera do século XIX, durante um razoável período de sua infância. Não se sabe exatamente com quantos anos foi deixado lá. Entretanto, autores mencionam a possibilidade de ter sido por volta dos dois aos cinco anos de idade (SAKS, 2005; SKUSE, 2004).

A história, como apresentada no filme, tem início com o personagem preso pelos pés, num subsolo onde dormia sobre palhas com um pequeno cobertor. Suas roupas eram rotas, e sua calça não tinha a parte traseira.

A autobiografia de Kaspar Hauser ${ }^{2}$ (HAUSER, 2003) corrobora as imagens do filme de que ele era alimentado a pão e água por um homem e acrescenta que a água, às vezes, tinha um sabor estranho e o fazia adormecer. Ao acordar, observava suas roupas trocadas e as unhas aparadas. Sua única distração era um cavalinho de brinquedo. Conforme o relato, nunca havia visto outra pessoa, até certo dia em que aquele que ele acreditava ser seu cuidador entrou no porão, colocou um banquinho diante dele e um lápis

${ }^{2}$ Conforme apresentada no blog <http://kasparbio.blogspot.com.br/2009/04/sobre-vida-de-kasparhauser-escrito-por.html>. Acesso em 10 dez. 2012. 
em sua mão. O homem repetiu a palavra 'escrever', segurando sua mão, e conduziu-a para que escrevesse seu nome, até que, por fim, Kaspar pode imitar. Depois disso, mostrando-lhe o cavalinho de brinquedo, pronunciou a palavra 'cavalo', até que Kaspar a reproduzisse oralmente. Imediatamente, prometeu-lhe que se aprendesse a escrevê-la, ganharia um igual.

Sem deixar claro o período de tempo decorrido, o filme mostra um homem trazendo roupas para Kaspar (00:06:30) ${ }^{3}$, e após vesti-lo, amarrando suas mãos e carregando-o nas costas para fora do porão. Ao sair, o jovem sofria forte incômodo nos olhos devido à claridade e, após um tempo sendo carregado até o alto de uma colina, foi deitado no chão. Vendo que não conseguiria continuar a carregá-lo, o homem resolveu ensinar-lhe a caminhar - o que lhe foi muito penoso. Para incentivá-lo, repetia-lhe a frase: "Devo me tornar tão bom cavaleiro quanto meu pai foi", frisando as palavras 'cavaleiro' e 'pai', até que Kaspar as repetisse.

Segundo sua biografia (HAUSER, 2003), ele repetiu 'cavalo' e 'casa', porque a palavra 'cavalo' o fazia lembrar-se do seu cavalinho de brinquedo e do porão onde vivia e para onde desejava voltar. $\mathrm{O}$ homem, desconhecendo seu real interesse, prometeu-lhe que, em breve, ganharia um cavalo bonito de seu pai. Porém, ele não dava indícios de compreender o significado de 'pai'. A narrativa acrescenta que, no caminho, sempre que chorava de dor nos olhos e nos pés, repetia aquelas palavras, e seu cuidador o incentivava a caminhar, mencionando que, se assim fizesse, ganharia o cavalo. De acordo com o relato, o homem seguia repetindo as palavras até que, após algumas paradas para descansar, Kaspar foi colocado em pé e levado até a praça da cidade de Nürnberg (na atual Alemanha). Recebeu, então, uma carta de seu cuidador, que novamente lhe repetiu as palavras e o abandonou ali, em pé, parado, com a carta na mão (HAUSER, 2003).

${ }_{3}$ Momento do filme em que ocorre o fato narrado.
Cenas do filme mostram que Kaspar permaneceu estático em frente à praça, como se estivesse em choque, observando coisas que nunca tinha visto e sendo observado por moradores curiosos que não entendiam seu comportamento. Até que um dos moradores aproximou-se, falou com ele e ofereceu-lhe ajuda. Contudo, ao ser questionado sobre o que fazia ali, Kaspar só conseguia repetir o que havia memorizado: as palavras: 'cavalo' e 'como meu pai foi'. O homem perguntou-lhe se vinha de Regensburg, ao que ele repetiu a palavra 'Regensburg'. Ele foi então encaminhado ao oficial da cavalaria, a quem a carta em suas mãos estava endereçada e que o acomodou junto com cavalos, e seguiu repetindo a palavra 'cavalo'.

Ainda de acordo com o filme, os líderes da cidade procuravam entender como ele havia aparecido na cidade. A carta mencionava que ele fora abandonado por sua mãe e deixado aos cuidados de um camponês que não tinha como criá-lo. Ela recomendava que não o maltratassem, pois não sabia se comunicar oralmente, apesar de ter sido ensinado a ler e escrever algumas palavras. Perguntam-lhe quem era, e ao perceber que não respondia, deramlhe caneta e papel para que escrevesse seu nome. Kaspar foi entregue pelos policiais a uma família que passou a cuidar dele e lhe ensinar algumas palavras. No início, ele deu conta de formar somente sentenças simples com a ajuda das crianças da casa, mas não conseguia elaborar orações complexas, nem mesmo repetir várias sentenças consecutivas.

Segundo Saboya (2001, p. 110), Kaspar pedia, "muitas vezes, [...] para contar histórias que imaginava, mas não conseguia verbalizar o conteúdo pensado". Ele apresentava também dificuldades para distinguir os sonhos da realidade.

Herzog mostra em seu filme que, após algum tempo, o jovem passou a morar com um estudioso que se interessou em acompanhá-lo eajudá-lo em sua socialização. A partir daí, ele desenvolveu várias habilidades, como a música e a escrita. Em conversa com seu tutor, Kaspar queixava-se de que tudo era 
muito difícil para ele. Mas, o tutor chamava sua atenção para o fato de que, em apenas dois anos de tutoria, Kaspar havia aprendido muitas coisas. Esse fato remete ao argumento gerativista da pobreza de estímulo (CHOMSKY, 2009), à capacidade dos falantes de, a partir de um número reduzido de informações, elaborar um número infinito de composições de frases nunca antes ouvidas. Contudo, sua capacidade de abstração parece comprometida devido a lacunas no processo de integração entre o pensamento e a linguagem, causadas pela falta de interação social (ambiental) a que foi exposto. Conforme Quadros (2008, p. 59), "A interação entre fatores ambientais e biológicos explica o uso que a criança faz da linguagem, tanto com relação à sua compreensão como com a sua produção da linguagem". Tais lacunas de capacidade de abstração do personagem podem ser exemplificadas pelo diálogo travado entre ele e seu tutor $(01: 01: 04)^{4}$ :

(K. Hauser): - Não entendo. Só um homem muito grande poderia ter construído isso (ele olha para a torre). Eu gostaria de conhecê-lo.

(Tutor): - Não é preciso ser tão grande para construí-la, pois existem andaimes. Entenderá quando o levar a uma construção. Você morou nesta torre, atrás daquela janela. Não se lembra?

(K. Hauser): - Isso não é possível, pois só tem alguns passos de largura. Quando estou dentro do quarto e olho para a direita, a esquerda, a frente e para trás, só enxergo o quarto. Quando olho para torre e depois me viro, a torre desaparece, então o quarto é maior que a torre.

Esse diálogo demonstra a dificuldade que Kaspar tinha para compreender ideias e conceitos que exigissem abstração. Conforme destaca Saboya (2001):

${ }_{4}^{4}$ Momento do filme em que ocorre o fato narrado.
Kaspar Hauser parece não entender as explicações que lhe dão. As pessoas impõem todos os tipos de signos a ele, na certeza de que compreenderá o insólito ambiente que o cerca. Como K. Hauser poderia compreender o significado das palavras e que elas representam coisas, se não passou por um processo de aprendizado e socialização necessários para que compreendesse a representatividade dos signos? (SABOYA 2001, p. 110).

Quadros (2008) chama a atenção para o fato de que toda criança, tendo em vista que dispõe da Gramática Universal, ao deparar-se com o ambiente, em contextos normais, vai adquirir a linguagem, tendo que aprender, obviamente, as palavras de sua língua para estruturar seu léxico mental. Entretanto, como a linguagem humana é muito complexa e envolve vários níveis no sistema linguístico, ela passará por estágios de aquisição, e, caso não tenha em sua sociedade a chance de acessá-la, "isso poderia implicar problemas posteriores, se tal capacidade se tornasse necessária após esse período" (p. 80). Como podemos observar na história de Kaspar, ele não adquiriu plenamente a linguagem no período ideal, ou crítico, conforme Lennenberg (1967) citado por Quadros (2008), o que possivelmente dificultou seu desenvolvimento do pensamento abstrato, isto é, de pensar sobre coisas que ainda não se conhece ou que não são concretas, bem como estabelecer hipóteses, avaliar e fazer escolhas. Para Saboya (2001):

A forma como Kaspar Hauser compreende o mundo e se relaciona com ele indica que a percepção depende sobretudo da prática social. Sabemos que do nascimento à adolescência, K. Hauser esteve isolado de qualquer contexto ou prática social. 0 que podemos verificar no seu percurso de desenvolvimento psicológico é que a despeito da ação da linguagem (adquirida na fase adulta) ou de um eventual "potencial" inato, K. Hauser não consegue captar o mundo como o faz a sociedade que o cerca, ou seja, decodifica à sua maneira com uma lógica diferente da estabelecida, a significação do mundo. Fica evidente, então, que o seu sistema perceptual está desaparelhado de uma prática social necessária para gestar o referencial cultural de interpretação da realidade (SABOYA, 2001, p. 111, grifo nosso). 
As habilidades por ele desenvolvidas, ainda que limitadas, despertaram o interesse e a curiosidade de muitos intelectuais, que vinham de longe, a fim de investigar sua capacidade de raciocínio.

Examinando o comportamento linguístico do personagem, observase que, com o passar do tempo, ele conseguiu elaborar algumas sentenças complexas para expressar seus pensamentos e sentimentos, mostrando razoável domínio sintático, fonético e semântico. Entretanto, conforme Botha (1981), seu desempenho linguístico, ao que tudo indica, sofreu limitações devido a fatores relacionados à aquisição tardia da linguagem.

Kaspar, de acordo com o filme, viveu na casa do professor até sua morte, que, segundo Saboya (2001), ocorreu por volta do ano de 1833.

\section{0 enigma linguístico de Kaspar Hauser e sua relação com o gerativismo}

Alguns pressupostos gerativistas sobre a aquisição da linguagem e a competência linguística podem ser identificados por meio da observação do desenvolvimento linguístico de Kaspar Hauser. Sua biografia não traz informações quanto à idade que tinha quando foi aprisionado no porão onde viveu grande parte de sua vida. Contudo, alguns autores afirmam que ele teve contato linguístico significativo antes de ser encarcerado. Sacks (2005, p. 23-24), por exemplo, diz que Kaspar foi dado por sua mãe viúva a uma família quando tinha seis meses de idade e que, "cerca de quatro anos mais tarde, passaria a mantê-lo isolado num porão, amarrado por correntes". Esses dados estabelecem uma relação com o princípio gerativista da pobreza de estímulo, que se refere à ideia de que a criança, mesmo exposta a uma quantidade limitada de dados linguísticos, adquire a gramática gerativa de sua língua, colocando em funcionamento princípios que indutivamente não poderia ter obtido.
Chomsky (2009, p. 38) argumenta que "desde os estágios mais iniciais a criança sabe muito mais do que a experiência ofereceu a ela" e que existe um período de pico da aquisição da linguagem quando "a criança adquire uma palavra por hora, mesmo em condições limitadas e sob condições muito ambíguas". Segundo Lennerberg (1967) apud Rosa (2010, p. 82), "parece que mesmo uma curta exposição à linguagem [...] é suficiente para propiciar à criança algum fundamento sobre o qual muito da linguagem pode se basear posteriormente". Nota-se isso no caso de Kaspar, visto haver suspeitas de que ele já houvesse aprendido um pouco da língua antes de ser confinado, algo relativo ao conhecimento linguístico "de uma criança de três anos" (SACKS, 2005, p. 66). Uma vez que, como o mesmo autor expõe, ao ser encontrado, Kaspar "não falava mais que seis palavras, cerca de quinze meses mais tarde era capaz de enunciados complexos como qualquer adulto". Essa rapidez na produção linguística deve-se, segundo o gerativismo, ao fato de ele já ter ativado seu DAL num breve período de sua infância.

Outros aspectos da Gramática Universal internalizada podem também ser observados no filme, a partir do momento em que Kaspar começa a conviver com a família do carcereiro de Nürnberg. Suas primeiras enunciações acontecem quando ele passa a interagir com as crianças da casa. Nos enunciados de Kaspar, a princípio, estão presentes apenas palavras soltas que, com o decorrer do tempo, dão início a estruturas de sentenças simples e, posteriormente, complexas.

Conforme Chomsky (2005, p. 31), cada linguagem é o resultado da interrelação de dois fatores: o estado inicial e o curso da experiência. Podemos conceber o estado inicial como um "sistema de aquisição da linguagem" que toma a experiência como input e fornece a linguagem como output - um output que é internamente representado na mente/cérebro. Para o autor, a interlocução daqueles que se relacionam com a criança e sua comunicação verbal com ela estimulam os mecanismos de aquisição, ainda que não 
definam as características últimas alcançadas pelo sistema gramatical (CHOMSKY, 1970, apud RAPOSO, 1992).

Cenas do filme demonstram que, apesar de ter começado a desenvolver sua habilidade comunicativa a partir da interação com outras pessoas, Kaspar não adquiriu o domínio total dos recursos da língua aprendida, tais como aspectos fonéticos (traços e acentos), tendo em vista não ter obtido a mesma entonação da fala dos nativos de Nürnberg. Lyons (2009) explica esse fato, ao dizer que existe uma idade crítica para a plena aquisição da linguagem e que, a não ser que ela seja adquirida até a fase em que a criança chega à referida idade, tornar-se-á mais difícil sua aquisição, limitando-a em algum de seus aspectos.

Estudos de Slobin (1980, p. 175) também têm mostrado que o hemisfério esquerdo do cérebro está "predisposto a adquirir a língua num estágio apropriado de maturação". Esse autor diz também que "a idade crítica ainda precisa de clara definição: alguns aspectos da evolução da língua parecem seguir um atalho aos cinco anos de idade; outros na puberdade". Quadros (2008, p. 80) ainda acrescenta que "as capacidades latentes são acessadas depois do período crítico", embora por caminhos diferentes aos da criança.

Com relação a isso, Chomsky (1997) defende:

A faculdade da linguagem se encaixa dentro da arquitetura maior da mente/ cérebro. Ela interage com outros sistemas, que impõe condições que a linguagem deve satisfazer se for para ser de todo estável. Estas podem ser pensadas como "condições de legibilidade", no sentido que outros sistemas precisam ser capazes de "ler" as expressões da língua e delas fazer uso para o pensamento e a ação (CHOMSKY, 1997, s/p.).

O filme apresenta Kaspar tendo seu cérebro extraído para estudos de anatomia, depois de morrer. Esses estudos revelaram que seu hemisfério direito era maior que o esquerdo, o que poderia explicar suas habilidades musicais, já que essas são processadas pelo hemisfério direito. Isso remete ao que Lyons (2009, p. 185) chama de lateralização, isto é, o "processo através do qual um dos hemisférios do cérebro é especializado para o desempenho de certas funções". De acordo com o mesmo autor, "a aquisição da linguagem começa mais ou menos ao mesmo tempo em que a lateralização e completase normalmente, no que diz respeito ao essencial, quando o processo de lateralização termina" (p. 185). Lyons faz uma comparação entre as principais funções dos hemisférios cerebrais humanos, mostrando que o esquerdo é responsável pela interpretação de sintagmas gramaticalmente complexos e por processar os sons da fala. Ele é melhor para o pensamento associativo e para o raciocínio lógico, além de abrigar a parte mais distintivamente linguística da linguagem que deve ser adquirida antes da idade crítica. Isso pode ser um indício das limitações linguísticas de Kaspar especialmente relacionadas ao seu desempenho linguístico.

A história de Kaspar Hauser continua sendo um enigma em muitos aspectos, especialmente no aspecto linguístico, em que existem muitas lacunas devido à falta de registros específicos sobre o assunto. Todavia, tanto o filme quando as demais fontes possibilitam utilizá-la para pensar algumas questões e fazer relações com pressupostos das teorias linguísticas.

\section{Considerações finais}

O presente trabalho examinou a trajetória linguística do protagonista do filme $O$ Enigma de Kaspar Hauser, relacionando-a aos principais conceitos de aquisição da linguagem, conforme postulados pelo gerativismo. Buscou perceber como eles se revelam na prática de um falante que adquiriu tardiamente a linguagem verbal.

Segundo a Teoria Gerativa, é possível que alguém que ficou afastado do contato com outros humanos, como foi o caso de Kaspar, desenvolva a linguagem verbal tardiamente, entretanto, com algumas limitações. Como 
postula o gerativismo, ao ser colocado em contato com falantes da língua alemã, o personagem acessou sua gramática internalizada, mesmo que, para esse processo, seu cérebro tenha utilizado outros caminhos. Isso, devido ao fato de haver passado seu período crítico para aquisição de uma língua, ou seja, aquele mais sensível à aquisição da linguagem que se inicia por volta dos dois anos de idade e se encerra por volta da puberdade, conforme Lennenberg (1967) apud Quadros (2008).

A análise indicou que o indivíduo retratado pelo filme se desenvolveu linguisticamente a partir do momento em que foi posto em contato com outras pessoas e que, mesmo com um input limitado, conseguiu colocar em funcionamento princípios que, indutivamente, não poderia ter obtido e desencadear informações linguísticas (output) ilimitadas. Para Chomsky, esse fenômeno pode ser explicado pelo argumento da "pobreza de estímulo", isto é, "falantes normais das línguas naturais atingem o estágio maduro de suas línguas durante um pequeno período de exposição a dados fragmentários, incompletos e inconsistentes" (GONÇALVES, 2007, p. 4). A Teoria Gerativa não descarta, portanto, a influência do meio na aquisição da linguagem, já que são as situações comunicativas que propiciam a existência de input e a possibilidade de output linguístico, materializado pelo desempenho linguístico.

A análise do percurso linguístico de Kaspar Hauser, como apresentado no filme e nos demais documentos sobre sua vida, corrobora o pressuposto gerativista que assegura haver uma gramática internalizada, inata e específica da espécie humana que possibilita seu desenvolvimento linguístico.

Kaspar conseguiu adquirir algum comportamento social e linguístico da sociedade em que fora inserido. No entanto, sabe-se que sua aceitação nunca foi completa, pois sua vida um mistério. Isso fica evidente, quando na lápide de Kaspar Hauser, no cemitério de Ansbach, na Alemanha, há uma inscrição que diz: "Hic occultus occultu uccisus est.", que quer dizer:
"Aqui jaz um desconhecido assassinado por um desconhecido" (SABOYA, p. 115), sua aparição na comunidade e sua vida foram marcadas por mistérios. Essas palavras em sua lápide mostram a trajetória enigmática de sua vida e morte.

\section{Referências}

BLIKSTEIN, Izidoro. Kaspar Hauser, ou a fabricação da realidade. 9. ed. São Paulo: Cultrix, 2003.

BOTHA, Rudolf P. The Conduct of Linguistic Inquiry: A Systematic Introduction to the Methodology of Generative Grammar. The Hague: Mouton Publishers, 1981.

CHOMSKY, Noam. Novos Horizontes no Estudo da Linguagem. D.E.L.T.A., v. 13, n. especial, p. 73-92, 1997.

. Arquitetura da linguagem. Nirmalangshu Mukherji, Bibudhendra Narayan Patnaik e Rama Kant Agnihotri (Org.). Tradução Alexandre Morales e Rafael Ferreira Coelho. Bauru, SP: Edusc, 2008.

. Linguagem e mente. Trad. Roberto Leal Ferreira. São Paulo: UNESP, 2009.

GLENDAY, Candice. A Lingüística de Chomsky em contraposição ao Estruturalismo e ao Behaviorismo. Revista Inter Science Place, v. 2, n. 08, s/p., 2009.

GONÇALVES, Rodrigo T. Chomsky e o aspecto criativo da linguagem. Revista Virtual de Estudos da Linguagem - ReVEL, v. 5, n. 8, p. 1-13, 2007.

HAUSER, Kaspar. Autobiografia. In: Christian Burgois (Org.). Kaspar Hauser: écrits de et sur Kaspar Hauser, 2003. Tradução de Elton P. A autobiografia de Kaspar Hauser. Disponível em: http://kasparbio.blogspot.com.br. Acesso em: 10 dez. 2012.

HERZOG, Werner. O Enigma de Kaspar Hauser. Título original: Jeder für sich und Gott gegen alle [filme - vídeo]. Direção e produção: Werner Herzog. Alemanha Ocidental. 1974. Cor. 110 min. Disponível em: <https://www.youtube.com/watch?v=geug75xNoAo>. Acesso em: 10 set. 2012.

LYONS, John. Linguagem e Linguística: uma introdução. RJ: LTC, 2009.

QUADROS, Ronice Müller de. O paradigma gerativista e a aquisição da linguagem. In: QUADROS, Ronice Müller de; FINGER, Ingrid. Teorias de aquisição da linguagem. Florianópolis: Ed. da UFSC, 2008. p. 45-82. 
RAPOSO, Eduardo. Teoria da Gramática: a faculdade da linguagem. Lisboa: Caminho, 1992.

ROSA, Maria Carlota. Introdução à (Bio)Linguística: linguagem e mente. São Paulo: Contexto, 2010.

SABOYA, Maria Clara L. O Enigma de Kaspar Hauser (1812?-1833): uma abordagem psicossocial. Psicologia. USP, v. 12, n. 2, São Paulo, p. 105-116, 2001.

SACKS, Oliver. Vendo Vozes: uma viagem ao mundo dos surdos. São Paulo: Cia das Letras, 2005.

SKUSE, David H. Extreme Deprivation in Early Childhood. In: BISHOP, Dorothy; MOGFORD, Kay (Ed.). Language Development in exceptional circumstances. Hiove \& New York: Psychology Press, 2004. p. 29-46.

SLOBIN, Dan Isaac. Psicolinguística. São Paulo: EDUSP, 1980.

TRASK, Robert Lawrence. Dicionário de Linguagem e Linguística. Trad. Rodolfo Ilari. São Paulo: Contexto. 2004.

VIOTTI, Evani. Introdução aos Estudos Linguísticos. Florianópolis, 2008. Disponível em: <http://www.libras.ufsc.br/colecaoLetrasLibras/eixoFormacaoBasica/estudos Linguisticos/assets/317/TEXTO_BASE__VVERSAO_REVISADA.pdf>. Acesso em: 10 set 2012.

Recebido em 18/01/2017.

Aceito em 20/09/2017 